\title{
Influence of Performance Attributions on Discounting and Devaluing Among High School Students: Does Academic Self-esteem Mediate?
}

\author{
Habil Otanga (Corresponding author) \\ Department of Psychology, University of Nairobi \\ Kenya \\ E-mail: otangahabil@gmail.com
}

Received: May 2, 2019 Accepted: May 21, 2019 Published: June 12, 2019

doi:10.5296/ijld.v9i2.14739 URL: https://doi.org/10.5296/ijld.v9i2.14739

\begin{abstract}
Although considerable research on psychological disengagement exists, there is less focus on the influence of performance attributions. The purpose of the present study was to investigate the extent to which performance attributions influence psychological disengagement, measured as discounting and devaluing; and whether academic self-esteem mediates the relationship. Four hundred and forty nine students (206 males and 243 females) whose age ranged from $15-19$ years $(M=17.20, S D=1.09)$ from 12 urban high schools in Mombasa, Kenya participated in the study. Using a questionnaire, participants' performance attributions, academic self-esteem, discounting and devaluing were measured. Data collected were analyzed using SPSS. Findings show significantly higher discounting than devaluing; significant indirect effects of external attributions on devaluing; and of stable and unstable attributions on discounting and devaluing through academic self-esteem. Practical implications of findings and directions for future research are discussed.
\end{abstract}

Keywords: discounting, devaluing, psychological disengagement, academic self-esteem, performance attributions

\section{Introduction}

Students' poor achievement and loss of interest in school is an issue of concern. Cases of absenteeism and truancy, putting less time in schoolwork and viewing school as a nuisance are increasingly reported (Osborne, 2001; Trout, 1997). Such learners may be said to be psychologically disengaged from the academic domain, either via discounting or devaluing. In Kenya for instance, adolescents in the Coast region attend school erratically and drop out in 
order to engage in non-academic activities (Jones, 2006). Secondly, students in Kenyan schools are likely to lose motivation following failure because of the ranking system in all school examinations. Students ranked poorly on the termly merit list may attribute internal and stable reasons for their poor performance which has implications for subsequent motivation. Being ranked highly is important due to the importance attached to educational achievement as a means to securing employment opportunities. To understand the underlying motivational basis for poor achievement and dropout, the current study examines whether performance attributions explain psychological disengagement among high school students in Mombasa, Kenya.

The current study seeks to contribute to the literature in three ways. First, whilst existing research suggests that psychological disengagement from academics is determined by negative feedback, there is much less evidence on the role of performance attributions. The cause that students attach to feedback predicts shifts in domain-specific esteem; and consequently, has implications for disengagement (Fishbach \& Finkelstein, 2012). Secondly, previous studies among minority groups focusing on the role of ethnic identity (Regner \& Loose, 2006; Strambler \& Weinstein, 2010; Verkuyten \& Thijs, 2004); and negative stereotypes (Major, Spencer, Schmader, Wolfe, \& Crocker, 1998; Schmader, Major, \& Gramzow, 2001; Steele, 1992) suggest that variations in psychological disengagement are due to group status as minorities. To understand whether psychological disengagement is specific to minorities and other special groups only, empirical data from majority populations is needed. Finally, compared to college students, fewer studies have focused on adolescents (Stephan, Caudroit, Boiche, \& Sarrazin, 2010; Regner \& Loose, 2006; Verkuyten \& Thijs, 2004) yet they also face equal risk of academic disengagement.

\subsection{Psychological Disengagement}

Psychological disengagement is a defensive detachment of self-esteem from outcomes in a particular domain, such that feelings of self-worth are not dependent on success or failure in that domain (Major et al., 1998). Accordingly, negative feedback in a domain where an individual's self-worth is staked leads to disengagement only if self-worth is threatened by a lowered self-evaluation in that domain (Osborne, 2001). Psychological disengagement is defined in terms of two separate processes. The first involves discounting the validity of feedback one receives (Loose, Regner, Morin, \& Dumas, 2012; Schmader et al., 2001). The second process involves devaluing the domain such that outcomes in the domain are no longer viewed as relevant or important to how an individual defines the self (Crocker \& Major, 1989; Major \& Schmader, 1998; Schmader et al., 2001). It involves decreasing the importance of competencies in the threatening domain for the self so that success or failure in the domain does not matter anymore (Steele, 1997). Both processes are likely to be evoked in evaluative situations when failure occurs, for instance, in examinations, that threaten individuals' sense of self-worth (Regner \& Loose, 2006; Stephan et al., 2010; Verkuyten \& Thijs, 2004).

Whereas tests in school are intended to evaluate learners' level of academic achievement, for some learners, tests are a threatening situation because of implications on self-worth evaluation (Crocker, Luhtanen, Cooper, \& Bouvrette, 2003). It therefore follows that students are apt to 
experience changes in academic self-esteem depending on their performance and are likely to discount performance feedback or devalue academic achievement to maintain self-worth (Osborne, 2001). Correlation studies (Major \& Schmader, 1998; Schmader et al., 2001) show that the two processes are not adopted simultaneously. The more individuals discount feedback, the more likely they are to devalue academic achievement (Nussbaum \& Steele, 2007; Regner \& Loose, 2006; Strambler \& Weinstein, 2010). However, it is difficult to generalise these findings because of the special characteristics of samples selected from elite universities (Nussbaum \& Steele, 2007); and ethnic minority populations suffering stereotype threat (Beaton, Tougas, Rinfret, \& Monger, 2014; Major \& Schmader, 1998; Osborne, 1995, 1997, 2001; Regner \& Loose, 2006; Steele, 1992; Verkuyten \& Thijs, 2004). Therefore, this study hypothesised that higher discounting than devaluing would be reported in this sample not expressly identified as a minority population.

\subsection{Performance Attributions and Psychological Disengagement}

According to Weiner $(1985,2010)$, performance attributions predict achievement outcomes. Respective attributions have implications for future task motivation and expectancy of success and failure. For instance, if causes can be modified, for instance internal attributions of effort or external attributions of luck, failure does not negatively influence future expectancy though self-esteem is lowered. However, if failure outcomes are attributed to stable causes, for instance, ability or task difficulty, future outcomes are certain through lowering self-esteem because such attributions infer personal responsibility for failure (Perry, Hechter, Menec, \& Weinberg, 1993). In fact, the negative effects of stable attributions for failure predict the decision to drop out of school (Weiner, 2010).

It therefore follows that how a student approaches success and failure plays a key role in the cognitive consequences that follow (Covington, 1984, Covington \& Omelich, 1985). For instance, whereas attributing negative outcomes to unstable causes such as effort increases motivation and perseverance, attributing them to stable causes such as ability weakens motivation (McFarland \& Ross, 1982) and is likely to be highly correlated with discounting and devaluing. Positive feedback on academic performance predicts increased task motivation if success is attributed to internal and unstable causes such as effort. Similarly, task motivation and future expectancy increases if negative feedback is attributed to an external factor like test difficulty (Weiner, 2010) or an internal factor that is unstable like lack of effort. The threat to self-worth resulting from one's attributions leads to development of self-serving biases including discounting and devaluing. Overall, this approach suggests a two-edged effect of feedback depending on one's attributions.

An increasing body of literature provides support for the hypothesis that attributions shape individuals' perceptions of the causes of outcomes (Crocker, Voekyl, Testa, \& Major, 1991; Ruggiero \& Taylor, 1997), that is, individuals' reactions are interpreted for favourable implications to the self (Blaine \& Crocker, 1993). Earlier research on the mechanisms through which attributions influence self-esteem maintenance focused on the link between outcomes, attributions and affect. For instance, McFarland and Ross (1982) found that undergraduates at the University of Waterloo attributed failure to task factors. Subjects in the success conditions 
experienced more pleasant affect than subjects in the failure conditions. Additionally, subjects who attributed failure to the task reported more pleasant affect than subjects who attributed failure to lack of ability. However, while most of the research on the relationship between performance attributions and psychological disengagement has been done in Europe and USA mostly among college students, fewer studies among adolescents are available. Second, despite the existing body of research, the influence of performance attributions on psychological disengagement remains understudied among some populations.

\subsection{Academic Self-Esteem and Psychological Disengagement}

Success in an important domain increases self-worth evaluation while failure denotes incompetence and is devastating for feelings of worth (Covington, 1984; Crocker \& Wolfe, 2001; Osborne, 1995). For students, success in the academic domain is important for overall self-worth evaluation and subsequent motivation (Crocker et al., 2003; Osborne, 1997; 1995). Higher academic self-esteem corresponds to higher motivation in subsequent tasks. When students psychologically disengage from the academic domain, academic self-esteem is disconnected from overall feelings of self-esteem. The need to protect is achieved via a range of cognitive responses, including discounting feedback and devaluing the domain.

The bulk of research on psychological disengagement shows that students delink academic self-esteem from self-worth evaluation in situations of failure (Crocker \& Luhtanen, 2003; Loose et al., 2012; Major \& Schmader, 1998; Regner \& Loose, 2006). However, another line of research suggests that attributions predict academic self-esteem. For instance, Major et al. (1998: Exp 2) in a study of undergraduate students at the University of New York at Buffalo found that in the context of failure, priming race increased African-American students' self-esteem. This indicates that external attributions for failure raises esteem, and provided evidence for a relationship between academic self-esteem and psychological disengagement. Put together, this finding suggests that academic self-esteem may be predicted by attributions to performance. Consequently, this study hypothesised that the relationship between performance attributions and psychological disengagement would be mediated by academic self-esteem.

\section{Method}

\subsection{Participants}

Four hundred and fifty three students (206 males and 247 females) from 12 urban schools in Mombasa, Kenya in the third grade of high school participated in the study. The students were aged between 15 and 19 years $(\mathrm{M}=17.20, \mathrm{SD}=1.09)$.

\subsection{Sampling Procedures}

Students from 12 randomly sampled public-funded and private schools representing $44.4 \%$ of high schools in Mombasa participated in the study. In Kenya, public-funded high schools fall into national and county categories. National schools admit highest performing students nationwide while county schools admit students from their local administrative regions. Private schools admit students using criteria set by respective school management boards. 


\section{$\Lambda$ Macrothink}

For this study, national and county (both public-funded) and private high schools were randomly sampled. It was expected that the sample would be representative of the majority population for two reasons: First, national schools admit students from all regions of the country; and, secondly, Mombasa is a cosmopolitan city and Kenya's second largest with a diverse population whose county and private schools admit students from different ethnic and social status groups. Written consent was sought prior to participation. Participants were informed that researchers carrying out this study were interested in understanding what motivates students in school. They were assured that information given would be anonymous. Ethical approval was received from the National Commission for Science, Technology and Innovation (NACOSTI).

\subsection{Measures}

The study was carried out over the course of one week during regular class hours. Instruments were administered in respective classrooms under supervision of the researcher. Upon entering the classroom, participants were asked to sign an informed consent form. They were then presented with a questionnaire containing items on attributions, academic self-esteem and psychological disengagement. Two items on age and sex of participants were also included.

\subsubsection{Performance Attributions}

The 24-item achievement subscale of the Multidimensional Multiattributional Causality scale (Lefcourt, von Baeyer, Ware, \& Cox, 1979) was used to measure performance attributions on a 5-point Likert scale $(1=$ strongly disagree and $5=$ strongly agree. Reliability analysis of the scale yielded an alpha of 0.75 . The subscale is categorized into four subgroups of ability, effort, context and luck each comprised of six items. For the current study, the subgroups were further categorized into locus and stability attributions. To derive the internal locus attributions, ability and effort subgroups were averaged while the external locus attributions' category was derived by averaging context and luck subgroups. Further, ability and context subgroups were averaged to derive stable attributions while effort and luck subgroups comprised the unstable attributions.

\subsubsection{Academic Self-Esteem}

The 7-item Performance Self-esteem subscale of the State Self-esteem scale (Heatherton \& Polivy, 1991) assessed academic self-esteem on a 5-point Likert scale ( 1 = strongly disagree and $5=$ strongly agree). Two sample items are, 'I feel confident about my abilities' and 'I feel frustrated about my academic performance'. Negatively worded items were reverse coded. Cronbach alpha was 0.71 .

\subsubsection{Psychological Disengagement}

This was measured using the Intellectual Engagement Inventory (Major \& Schmader, 1998) on a 5-point Likert scale $(1=$ strongly disagree and $5=$ strongly agree). Discounting was measured using four items: 'I feel that school examinations are fair tests of my abilities; 'In general, I feel that school examinations are a good measure of my intelligence'; Most examinations do not really measure what they are supposed to'; and 'I feel that school examinations are definitely 
biased against me'. The first two items were reverse coded and higher means indicated higher discounting. Devaluing was measured by four items: 'Being good at academics is an important part of whom I am'; 'I always feel good about myself when I do well on an academic test'; 'Academic success is not very valuable to me'; and 'It usually doesn't matter to me how I do in school'. Item 1 and 2 were reverse coded. Higher means indicated higher devaluing. Reliability analysis yielded an alpha of 0.67 for discounting and 0.68 for devaluing. After completing the task, students were afforded time to ask questions and seek any clarifications concerning the study. They were then thanked and dismissed.

\subsection{Data Analysis Procedure}

All analyses were done using IBM SPSS Statistics 25. Descriptive statistics, including means and standard deviations were calculated for all variables. Bivariate correlational analysis was conducted between the independent variables to examine the assumption of multicollinearity. Descriptive findings are presented in Table 1. Independent sample t-tests were used to examine gender differences in attributions, academic self-esteem and discounting and devaluing. Multiple regression analyses were conducted to determine how much variation in discounting and devaluing could be attributed to performance attributions at the 0.05 level of significance. To test the mediation model predicting that the influence of performance attributions on discounting and devaluing would be mediated by academic self-esteem, mediation analysis was conducted using the PROCESS macro for SPSS (Hayes, 2018). Results are reported for bootstrap significance tests using a bias-corrected 95\% confidence interval (CI) and employ a resample procedure of 5000 bootstrap samples. An estimate is considered statistically significant if the $95 \%$ CI does not contain zero.

\section{Results}

\subsection{Preliminary Analysis}

Four questionnaires were incomplete and were excluded from data analysis. The final sample comprised 449 participants (206 males and 243 females) whose age ranged from 15 -19 years $(\mathrm{M}=17.20, \mathrm{SD}=1.09)$. Zero-order correlations in Table 1 show that discounting and devaluing were significantly correlated, consistent with studies that show a hierarchical progression from the former to the latter. Unstable attributions were not significantly correlated with both discounting and devaluing. Negative correlations between academic self-esteem and both discounting and devaluing support the hypothesis that it is the lowered valuation of the academic domain that leads to psychological disengagement.

Significant gender differences were found in unstable, $t(447)=-3.09, p=.002$; and internal attributions, $t(447)=-2.36, p=.019$. In both cases, female students reported higher means. Significant gender differences were also found in devaluing, $t(447)=2.90, p=.004$, with higher reports among male students. No significant gender differences were found for stable and external attributions, academic self-esteem and discounting. No age differences were found for any of the variables measured. As predicted, significant differences were found between discounting and devaluing, $t(448)=22.67, p<.001$, with higher discounting $(M=$ $8.81, S D=3.01)$ than devaluing $(M=5.36, S D=2.13)$ reported. Students reported higher 
internal attributions $(M=36.27, S D=6.18)$ while external attributions were least reported $(M=$ $18.59, S D=7.98)$.

Table 1. Pearson product-moment correlation coefficients of variables (with means and standard deviations)

\begin{tabular}{lllllllll}
\hline Variables & Mean & SD & 1 & 2 & 3 & 4 & 5 & 6 \\
\hline Stable & 25.60 & 6.50 & - & & & & & \\
Unstable & 29.27 & 5.81 & $.46^{* *}$ & - & & & & \\
Internal & 36.27 & 6.18 & $.53^{* *}$ & $.59^{* *}$ & - & & & \\
External & 18.59 & 7.98 & $.74^{* *}$ & $.64^{* *}$ & .09 & - & & \\
ASE & 21.79 & 5.06 & $-.29^{* *}$ & $-.11^{*}$ & -.06 & $-.27^{* *}$ & - & \\
Discounting & 8.81 & 3.01 & $.19^{* *}$ & .04 & $-.14^{* *}$ & $.29^{* *}$ & $-.16^{* *}$ & - \\
Devaluing & 5.36 & 2.31 & .07 & -.06 & -.20 & $.17^{* *}$ & $-.17^{* *}$ & $.25^{* *}$ \\
\hline
\end{tabular}

Note. ASE: Academic Self-esteem; ${ }^{* *}$ Correlation significant at the 0.01 level (2-tailed); ${ }^{*}$ Correlation significant at the 0.05 level (2-tailed)

\subsection{Performance Attributions and Discounting and Devaluing}

Regression analyses show that respondents' stability attributions predicted discounting, $F(2$, $446)=9.31, p<.001$, and devaluing, $F(2,446)=3.34, p=.036$. Findings suggest that students are more likely to discount the validity of feedback in school if they hold stable as opposed to unstable attributions. A similar effect was also found in predicting devaluing. Locus attributions also predicted discounting, $F(2,446)=28.07, p<.001$ and devaluing, $F(2,446)=$ $17.24, p<.001$. Similar to stability attributions, locus attributions influenced discounting and devaluing in opposite directions. Data supported the hypothesis posed.

\subsection{Mediation Analysis}

To test whether academic self-esteem mediates the influence of performance attributions on discounting and devaluing, analyses were conducted using the PROCESS macro for SPSS (Hayes, 2018). Separate analyses were done for discounting and devaluing respectively. Results are reported for bootstrap significance tests using a bias-corrected $95 \%$ confidence interval (CI) and based on a resample procedure of 5000 bootstrap samples (Model 4). Significance of the indirect effect is considered if the $95 \% \mathrm{CI}$ is entirely above zero. Unstandardized coefficients are reported.

The mediation model of internal attributions was significant for both discounting, $F(2,446)=$ $11.14, p<.001, \mathrm{R}^{2}=.05$; and devaluing, $F(2,446)=17.11, p<.001, \mathrm{R}^{2}=.07$. Internal attributions were significantly and negatively associated with both discounting and devaluing controlling for academic self-esteem. However, the indirect path through academic self-esteem 


\section{Macrothink}

International Journal of Learning and Development

ISSN 2164-4063

2019, Vol. 9, No. 2

was not statistically different from zero for discounting $(\mathrm{B}=.01, \mathrm{SE}=.01, \mathrm{CI}[-.003, .014]$ and devaluing $(\mathrm{B}=.00, \mathrm{SE}=.01, \mathrm{CI}[-.002, .011]$. Table 3 reveals evidence of a suppression effect for both discounting and devaluing.

External attributions were significantly and positively associated with discounting, $F(2,446)=$ $22.33, p<.001, \mathrm{R}^{2}=.09$, and devaluing, $F(2,446)=10.26, p<.001, \mathrm{R}^{2}=.04$, when academic self-esteem was included in the model. Higher external attributions predicted a reduction in academic self-esteem which in turn predicted high discounting and devaluing. The bootstrap $95 \%$ bias-corrected confidence intervals for the indirect path between external attributions and discounting was not significant $(\mathrm{B}=.01$, CI $[-.001, .020]$ while the path with devaluing (B $=.01, \mathrm{CI}[.002, .019]$ did not contain zero.

Significant direct effects of stable attributions on discounting, $F(2,446)=11.32, p<.001, \mathrm{R}^{2}$ $=.05$; and devaluing, $F(2,446)=6.32, p=.001, \mathrm{R}^{2}=.03$ were found. The coefficient for stable attributions went into insignificance when academic self-esteem was added to the model predicting devaluing, $F(2,446)=6.70, p=.001, \mathrm{R}^{2}=.03$ indicating that academic self-esteem fully mediated the association between stable attributions and devaluing. The indirect effect through academic self-esteem was significantly different from zero for discounting $(\mathrm{B}=.02, \mathrm{CI}$ $[.002, .030]$, and for devaluing $(\mathrm{B}=.02$, CI $[.006, .027]$.

The direct effect of unstable attributions was significant on discounting, $F(2,446)=5.82, p$ $=.003, \mathrm{R}^{2}=.03$; and devaluing, $F(2,446)=8.06, p<.001, \mathrm{R}^{2}=.04$, with academic self-esteem in the respective models. The $95 \%$ bias-corrected confidence intervals for the indirect effect of unstable attributions on discounting $(\mathrm{B}=.01$, CI $[.005, .020]$, and devaluing, $(\mathrm{B}=.01$, CI $[.001, .016]$ were above zero. Suppressor effects of academic self-esteem indicate that unstable attributions predicted a reduction in devaluing via an increase in academic self-esteem. Table 2 shows the coefficient values for the direct and indirect effects and the $95 \%$ bias-corrected confidence intervals for the indirect effects.

Table 2. Direct and indirect effects of performance attributions on discounting and devaluing

\begin{tabular}{lllllll}
\hline Predictor & \multicolumn{3}{c}{ Discounting } & \multicolumn{3}{c}{ Devaluing } \\
\hline & $\begin{array}{l}\text { Direct } \\
\text { effect }\end{array}$ & $\begin{array}{l}\text { Indirect } \\
\text { effect[95\%CI] }\end{array}$ & $\begin{array}{l}\text { Total } \\
\text { effect }\end{array}$ & $\begin{array}{l}\text { Direct } \\
\text { effect }\end{array}$ & $\begin{array}{l}\text { Indirect } \\
\text { effect[95\%CI] }\end{array}$ & $\begin{array}{l}\text { Total } \\
\text { effect }\end{array}$ \\
\hline Internal & $-.073^{*}$ & $.005[-.003, .014]$ & $-.068^{*}$ & $-.071^{* *}$ & $.004[-.002, .011]$ & $-.068^{* *}$ \\
External & $.100^{* *}$ & $.009[-.001, .020]$ & $.109^{* *}$ & $.034^{*}$ & $.010[.002, .019]$ & $.044^{* *}$ \\
Stable & $.074^{* *}$ & $.015[.002, .030]$ & $.088^{* *}$ & .007 & $.015[.006, .027]$ & .022 \\
Unstable & .009 & $.009[.005, .020]$ & .018 & -.029 & $.007[.001, .016]$ & -.022 \\
\hline
\end{tabular}

Note. $* p<.01 ; * p<.001$.

\section{Discussion}


Given the role of attributions in predicting subsequent motivation and task performance, the school context is a good setting to examine the use of performance attributions. Therefore, the purpose of the present study was to identify the process through which performance attributions explain psychological disengagement, measured as discounting and devaluing.

The findings of the study show that external and stable attributions significantly predict increase in discounting and devaluing through a reduction in academic self-esteem. Unstable attributions predict reduction in discounting and devaluing through increase in academic self-esteem. In summary, the findings suggest that the more students attribute their success and failure to causes that are external and stable, the more likely they are to discount feedback than their counterparts who believe that such causes are unstable. This finding supports earlier studies (Major et al., 1998; Verkuyten \& Thijs, 2004) which found that psychological disengagement occurred under external attributions, for instance, conditions of perceived disadvantage.

The finding that students were more likely to discount than devalue supports the prediction that devaluing unlike discounting, is a stable attribute that is unlikely to temporarily fluctuate (Crocker \& Major, 1989; Regner \& Loose, 2006) irrespective of attributions. These results suggest that in specific situations, students' unstable attributions help them to temporarily disengage their self-esteem from the academic domain without losing motivation by increasing academic self-esteem. Discounting feedback via attributing outcomes to unstable causes may therefore dampen the effect of failure without affecting underlying motivation. Hence, these findings show that when students attribute failure to factors external to them, and stable, they discount feedback but do not devalue the academic domain.

Findings provide evidence for the hypothesis that lowered esteem in a domain of worth predicts psychological disengagement. Mediation analyses show that students' stable and external attributions lowered academic self-esteem which then predicted discounting and devaluing. Whereas previous studies have found a direct link between students' grades in tests and psychological disengagement (Crocker et al., 2003; Major et al., 1998; Regner \& Loose, 2006), this study provides evidence that stable and external attributions lower academic self-esteem which then predicts psychological disengagement. Findings therefore support literature on self-serving biases in attributions (McFarland \& Ross, 1982). They show that students are more likely to take personal responsibility for successes than failures and hence impact on academic self-esteem when failure occurs (Perry et al., 1993). Overall, these findings show that students attribute success and failure in ways that validate the domains on which self-worth is contingent.

Further, results show that performance attributions and changes in self-esteem and psychological disengagement are linked; and that attributions can be manipulated for educationally beneficial outcomes. It is evident that changing students' attributions depends on the importance they place on the academic domain. To increase expectations about future performance (Weiner, 1985, 2010), unstable and external attributions for success outcomes need to be replaced with internal and stable attributions while for failure outcomes, stable outcomes need to be changed to unstable ones. This has the objective of increasing motivation 
and persistence through increase in self-esteem (Perry et al., 1993). School teachers may incorporate attributional retraining in classroom interactions.

This research has some limitations. Data should be interpreted considering that variables were self-reported. Respondents' social desirability concerns have to be considered in interpretation of the data. Secondly, the sample comprised high school students in a single level. Thirdly, the measures employed have not previously been tested in Africa which may undermine the strength of findings given cultural differences in value attached to educational achievement. Future research in diverse cultures is needed to test whether the effects of these variables can be replicated. Finally, due to the correlation nature of the study, caution should be taken making any causal interpretation of findings. Variables were measured at a single point in time yet could fluctuate with time. The study however, provides data that shows the linkages between students' attributions, academic self-esteem and psychological disengagement among students in Africa.

The current study provides impetus into school processes that influence students' attributions and academic self-esteem. Since it is evident that school tests threaten academic self-esteem, yet are necessary for evaluation, teachers must strive to strike the balance. It is therefore plausible that students irrespective of level will psychologically disengage for self-esteem maintenance when they hold external and stable attributions. Since the study employed a nationally representative sample, findings suggest that psychological disengagement is not limited to students from low socio-economic status or minorities only. Therefore, the study adds to the understanding of psychological disengagement among a previously understudied population in Africa.

\section{References}

Beaton, A. M., Tougas, F., Rinfret, N., \& Monger, T. (2014). The psychological disengagement model among women in science, engineering, and technology. British Journal of Social Psychology. http://dx.doi.org/10.1111/bjso.12092

Blaine, B., \& Crocker, J. (1993). Self-esteem and self-serving biases in reactions to positive and negative events: An integrative review. In R. F. Baumeister (Ed.), Self-esteem: The puzzle of low self-regard (pp. 55-85). New York: Plenum Press.

Covington, M. V. (1984). The self-worth theory of achievement motivation: Findings and implications. The Elementary School Journal, 85(1), 4-20. http://dx.doi.org/10.1086/461388

Covington, M. V., \& Omelich, C. L. (1985). Ability and effort valuation among failure-avoiding and failure-accepting students. Journal of Educational Psychology, 77, 446-459. http://dx.doi.org/10.1037/0022-0663.77.4.446

Crocker, J., Luhtanen, R. K., Cooper, M. L., Bouvrette, A. (2003). Contingencies of self-worth in college students: Theory and measurement. Personality Processes and Individual Differences, 85(5), 894-908. http://dx.doi.org/10.1037/0022-3514.85.5.894

Crocker, J., \& Major, B. (1989). Social stigma and self-esteem: The self-protective properties of stigma. Psychological Review, 96(4), 608-630. 
http://dx.doi.org/10.1037/0033-295X.96.4.608

Crocker, J., Major, B., \& Steele, C. (1998). Social stigma. In D. T. Gilbert \&

S. T. Fiske (Eds.), The handbook of social psychology (Vol. 2, 4th ed., pp. 504-553). Boston: McGraw-Hill.

Crocker, J., Voelkl, K., Testa, M., \& Major, B. (1991). Social stigma: The affective consequences of attributional ambiguity. Journal of Personality and Social Psychology, 60(2), 218-228. http://dx.doi.org/10.1037/0022-3514.60.2.218

Crocker, J., \& Wolfe, C. T. (2001). Contingencies of self-worth. Psychological Review, 108(3), 593-693. http://dx.doi.org/10.1037//0033-295X.108.3.593

Fishbach, A., \& Finkelstein, S. R. (2012). How feedback influences persistence, disengagement, and change in goal pursuit, In H. Aarts \& A. Elliot (Eds.), Goal-directed behaviour (pp. 203-230). New York: Psychology Press.

Hayes, A. (2018). Introduction to mediation, moderation, and conditional process analysis: A regression-based approach $2^{\text {nd }}$ Edition. New York: The Guilford Press.

Heatherton, T. F., \& Polivy, J. (1991). Development and validation of a scale for measuring state self-esteem. Journal of Personality and Social Psychology, 60(6), 895-910. http://dx.doi.org/10.1037/0022-3514.60.6.895

Jones, C. S. (2006). The extent and effect of sex tourism and sexual exploitation of children on the Kenyan coast. Nairobi: UNICEF.

Lefcourt, H. M., von Baeyer, C. L., Ware, E. E., \& Cox, D. J. (1979). The multidimensional-multiattributional causality scale: The development of a goal specific locus of control scale. Canadian Journal of Behavioural Science Review, 11(4), 286-304. http://dx.doi.org/10.1037/h0081598

Loose, F., Regner, I., Morin, A. J. S., \& Dumas, F. (2012). Are academic discounting and devaluing double-edged swords? Their relations to global self-esteem, achievement goals, and performance among stigmatized students. Journal of Educational Psychology, 104(3), 713-725. http://dx.doi.org/10.1037/a0027799

Major, B., \& Schmader, T. (1998). Coping with stigma through psychological disengagement. In J. K. Swim \& C. Stangor (Eds.), Prejudice: The target's perspective (pp. 219-241). San Diego, CA: Academic Press.

Major, B., Spencer, S., Schmader, T., Wolfe, C., \& Crocker, J. (1998). Coping with negative stereotypes about intellectual performance: The role of psychological disengagement. Personality and Social Psychology Bulletin, 24, 34-50. http://dx.doi.org/10.1177/0146167298241003

McFarland, C., \& Ross, M. (1982). Impact of causal attributions on affective reactions to success and failure. Journal of Personality and Social Psychology, 43(5), 937-946. http://dx.doi.org/10.1037/0022-3514.43.5.937 
Nussbaum, A. D., \& Steele, C. M. (2007). Situational disengagement and persistence in the face of adversity. Journal of Experimental Social Psychology, 43, 127-134. doi:10.1016/j.jesp.2005.12.007

Osborne, J. W. (2001). Academic disidentification: Unravelling underachievement among Black boys. In R. Majors (Ed.), Educating our Black children: New directions and practical approaches (pp. 45-58). London: Routledge.

Osborne, J. W. (1997). Race and academic disidentification. Journal of Educational Psychology, 89, 728-735. http://dx.doi.org/10.1037/0022-0663.89.4.728

Osborne, J. W. (1995). Academics, self-esteem and race: A look at the underlying assumptions of the disidentification hypothesis. Personality and Social Psychology Bulletin, 21, 449-455. http://dx.doi.org/10.1177/0146167295215003

Perry, R. P., Hechter, F. J., Menec, V. H., \& Weinberg, L. E. (1993). Enhancing achievement motivation and performance in college students: An attributional retraining perspective. Research in Higher Education, 34(6), 687-723. http://dx.doi.org/10.1007/BF00992156

Regner, I., \& Loose, F. (2006). Relationship of sociocultural factors and academic self-esteem to school grades and school disengagement in North African French adolescents. British $\begin{array}{lllll}\text { Journal of } \quad \text { Educational } & \text { Psychology, } & \text { 45, }\end{array}$ http://dx.doi.org/10.1348/014466605X83610

Ruggiero, K. M., \& Taylor, D. M. (1997). Why minority group members perceive or do not perceive the discrimination that confronts them: The role of self-esteem and perceived control. Journal of Personality and Social Psychology, 72(2), 373-389. http://dx.doi.org/10.1037/0022-3514.72.2.373

Schmader, T., Major, B. \& Gramzow, R. H. (2001). Coping with ethnic stereotypes in the academic domain: Perceived injustice and psychological disengagement. Journal of Social Issues, 57(1), 93-111. DOI: http://dx.doi.org/10.1111/0022-4537.00203

Steele, C. M. (1997). A threat in the air: How stereotypes shape intellectual identity and performance. American Psychologist, 613-629. http://dx.doi.org/10.1037/0003-066X.52.6.613

Steele, C. M. (1992). Race and the schooling of Black Americans. The Atlantic Monthly, 269(4), 67-78.

Stephan, Y., Caudroit, J., Boiche, J. \& Sarrazin, P. (2010). Predictors of situational disengagement in the academic setting: The contribution of grades, perceived competence, and academic motivation. British Journal of Educational Psychology, 81(3), 441-455. http://dx.doi.org/10.1348/000709910X522285

Strambler, M. J., \& Weinstein, R. S. (2010). Psychological disengagement in elementary school among ethnic minority students. Journal of Applied Developmental Psychology, 31, 155-165. http://dx.doi.org/10.1016/j.appdev.2009.11.006 


\section{Macrothink}

International Journal of Learning and Development

ISSN 2164-4063 2019, Vol. 9, No. 2

Trout, P. A. (1997). Disengaged students and the decline of academic standards. Academic Questions, 10(2), 46-56. http://dx.doi.org/10.1007/s12129-997-1067-3

Verkuyten, M., \& Thijs, J. (2004). Psychological disidentification with the academic domain among ethnic minority adolescents in The Netherlands. British Journal of Educational Psychology, 74, 109-125. http://dx.doi.org/10.1348/000709904322848842

Weiner, B. (2010). The development of an attribution-based theory of motivation: A history of ideas. Educational Psychologist, 45(1), 28-36. http://dx.doi.org/10.1080/00461520903433596

Weiner, B. (1985). An attributional theory of achievement motivation and emotion. Psychological Review, 92(4), 548-573. http://dx.doi.org/10.1037/0033-295X.92.4.548

\section{Copyright Disclaimer}

Copyright for this article is retained by the author(s), with first publication rights granted to the journal.

This is an open-access article distributed under the terms and conditions of the Creative Commons Attribution license (http://creativecommons.org/licenses/by/4.0/). 